\section{LUPUS SCIENCE\& MEDICINE}

\title{
High-risk coronary plaque in SLE: low- attenuation non-calcified coronary plaque and positive remodelling index
}

\author{
George Stojan (D) , ${ }^{1}$ Jessica Li, ${ }^{1}$ Matthew Budoff, ${ }^{2,3}$ Armin Arbab-Zadeh, ${ }^{4}$ \\ Michelle A Petri (D) ${ }^{5}$
}

To cite: Stojan G, Li J, Budoff M, et al. High-risk coronary plaque in SLE: low-attenuation noncalcified coronary plaque and positive remodelling index. Lupus Science \& Medicine 2020;7:e000409. doi:10.1136/ lupus-2020-000409

Received 21 April 2020 Revised 13 June 2020 Accepted 25 June 2020

\section{Check for updates}

(c) Author(s) (or their employer(s)) 2020. Re-use permitted under CC BY. Published by BMJ.

${ }^{1}$ Rheumatology, Johns Hopkins University, Baltimore, Maryland, USA

${ }^{2}$ Cardiology, David Geffen School of Medicine, Los Angeles,

California, USA

${ }^{3}$ Cardiology, UCLA, Los Angeles, California, USA

${ }^{4}$ Cardiology, Johns Hopkins University, Baltimore, Maryland, USA

${ }^{5}$ Division of Rheumatology, Johns Hopkins University School of Medicine, Baltimore, Maryland, USA

Correspondence to

Dr George Stojan; gstojan1@ jhmi.edu

\section{ABSTRACT}

Background Positive remodelling index and presence of low-attenuation non-calcified plaque (LANCP) are characteristic vessel changes in unstable coronary plaques. We sought to characterise these high-risk plaque features in patients with systemic lupus erythematosus (SLE) and to compare them with controls.

Methods A total of 72 patients who satisfied the SLICC classification criteria for SLE had coronary CT angiography (CCTA) studies, 30 of which had follow-up CCTA, as screening for occult coronary atherosclerotic disease in asymptomatic individuals. A total of 100 consecutive controls with no known history of lupus, heart disease or revascularisation who had two coronary $\mathrm{CT}$ angiograms at least 1 year apart were included in the study. These were asymptomatic patients referred by their primary physicians for screening of coronary artery disease and the screening interval was decided by the primary physicians. The methodology for image acquisition was identical.

Results LANCP burden at baseline was significantly greater in patients with SLE compared with controls. LANCP volume was significantly greater in patients over 60 years of age $(p<0.05)$ and in those with current prednisone dose $>10 \mathrm{mg} / \mathrm{day}$. LANCP burden remained stable over follow-up. There were no significant differences in remodelling index compared with controls.

Conclusion This is the first study describing high-risk CCTA features of coronary plaque in patients with SLE. Both LANCP and positive remodelling are common in SLE. These characteristic vessel changes may identify patients with SLE at increased risk of cardiovascular events and those in need for more frequent cardiac monitoring.

\section{BACKGROUND}

Low-attenuation non-calcified plaque (LANCP) and positive remodelling index are characteristic vessel changes in unstable coronary plaques. ${ }^{1}$

LANCP $(<30$ Hounsfield Units (HU) contain necrotic cores that are characterised by endothelial dysfunction, oxidative stress and inflammation. ${ }^{2}$ They have been shown to be a better predictor of future cardiovascular events compared with traditional cardiovascular risk factors in the general population. ${ }^{3}$
Coronary arterial remodelling describes changes of vessel size at the site of atherosclerotic lesions. ${ }^{4}$ Positive remodelling (expansion) of early lesions maintains lumen size despite plaque accumulation. ${ }^{5}$ This explains why these lesions might pass undetected by conventional angiography. Coronary artery plaques with positive remodelling have a higher lipid content and macrophage count, both markers of plaque vulnerability. ${ }^{6}$ Plaque rupture is often apparent at sites with only modest luminal stenoses but marked positive remodelling. ${ }^{7}$

When low-attenuation and positive remodelling coexist, the risk for future cardiovascular events is 11-22-fold higher than patients without these characteristics. ${ }^{18}$

Accelerated atherosclerosis leading to premature coronary artery disease remains the major cause of late death in systemic lupus erythematosus (SLE). ${ }^{9}$ We sought to characterise LANCP and positive remodelling index in patients with SLE.

\section{METHODS}

As previously described, ${ }^{10}$ the Hopkins Lupus Cohort is a prospective cohort study of predictors of lupus flare, atherosclerosis and health status in SLE. The study cohort includes all patients at the Hopkins Lupus Center who have a clinical diagnosis of SLE and give informed consent to participate in the study. Subjects enrolled in the cohort are followed quarterly or more frequently if clinically necessary. The clinical features, laboratory testing and damage accrual data are recorded at the time of entry into the cohort and are updated at subsequent visits. The Hopkins Lupus Cohort has been approved by the Johns Hopkins University School of Medicine Institutional Review Board and complies with the Health Insurance Portability and Accountability Act. All patients gave written informed consent. 
Table 1 Baseline demographic characteristics of patients with SLE and controls

\begin{tabular}{|c|c|c|c|}
\hline & $\begin{array}{l}\text { Patients with } \\
\text { SLE }(n=72)\end{array}$ & $\begin{array}{l}\text { Controls } \\
(n=100)\end{array}$ & $P$ value \\
\hline $\begin{array}{l}\text { Age at baseline, } \\
\text { mean (SD) }\end{array}$ & $\begin{array}{l}51.1 \\
(\mathrm{SD}=11.4)\end{array}$ & $66.3(\mathrm{SD}=9.6)$ & \\
\hline $\begin{array}{l}\text { Age at baseline } \\
\text { categories }\end{array}$ & & & $<0.0001$ \\
\hline$<45$ & 27 (37.5\%) & $2(2 \%)$ & \\
\hline $45-<60$ & 37 (51.4\%) & $25(25 \%)$ & \\
\hline$\geq 60$ & $8(11.1 \%)$ & 73 (73\%) & \\
\hline Sex & & & $<0.0001$ \\
\hline Female & 61 (84.7\%) & 24 (24\%) & \\
\hline Male & $11(15.3 \%)$ & 76 (76\%) & \\
\hline Ethnicities & & & 0.0003 \\
\hline $\begin{array}{l}\text { African } \\
\text { American }\end{array}$ & 17 (23.6\%) & $5(5.3 \%)$ & \\
\hline Caucasian & 51 (70.8\%) & 67 (71.3\%) & \\
\hline Other & $4(5.6 \%)$ & $19(20.3 \%)$ & \\
\hline Ever smoking & & & 0.8820 \\
\hline Yes & 24 (33.3\%) & 31 (34.4\%) & \\
\hline No & $48(66.7 \%)$ & 59 (65.6\%) & \\
\hline Hypertension & & & 0.9590 \\
\hline Yes & 47 (65.3\%) & 61 (64.9\%) & \\
\hline No & 25 (34.7\%) & $33(35.1 \%)$ & \\
\hline Diabetes & & & 0.0013 \\
\hline Yes & $2(2.8 \%)$ & $18(19.1 \%)$ & \\
\hline No & $70(97.2 \%)$ & $76(80.9 \%)$ & \\
\hline Statin use & & & $<0.0001$ \\
\hline Yes & 20 (27.8\%) & 63 (68.5\%) & \\
\hline No & $52(72.2 \%)$ & $29(31.5 \%)$ & \\
\hline
\end{tabular}

Sample sizes for each variable do not always add up to the total due to missing information in some patients.

SLE, systemic lupus erythematosus.

A total of 72 patients who satisfied the Systemic Lupus International Collaborating Clinics (SLICC) classification criteria for SLE ${ }^{11}$ had coronary CT angiography (CCTA) studies, 30 of which had follow-up CCTA (mean=3.77 years, $\mathrm{SD}=0.94$ years), for screening for occult coronary atherosclerotic disease in asymptomatic individuals. Follow-up CCTA was part of the study protocol for all patients but due to expiration of funding, follow-up CCTA was completed in 30 patients. Exclusion criteria included a serum creatinine level $\geq 1.2 \mathrm{mg} / \mathrm{dL}$, allergy to contrast material, pregnancy or history of angina, myocardial infarction or stroke attributable to atherosclerotic disease. CT images were acquired using a $320 \times 0.5 \mathrm{~mm}$-detector row CT system (Aquilion ONE, Canon Medical Systems, Otawara, Japan). Patient preparation included oral $(75-150 \mathrm{mg})$ metoprolol. Fifty to seventy millilitres of iodinated contrast (Iopamidol 370 or iohexol $350 \mathrm{mg}$ iodine $/ \mathrm{mL}$ ) was injected intravenously at $4.0-6.0 \mathrm{~mL} / \mathrm{s}$ for prospectively ECG-triggered acquisitions (typically $75 \%$ of the R-R interval). If coronary calcification was evident on angiographic images, a non-contrast CT acquisition was added to quantify calcium for the Agatston score. CT angiographic data were reconstructed to generate $0.5 \mathrm{~mm}$ slice thickness images with a $0.25 \mathrm{~mm}$ increment using both a standard (FC43) and a sharp (FC05) convolution kernel. Reconstructed images were transferred to a dedicated workstation for further analysis (Vitrea FX V.3.0 workstation, Vital Images, Minnetonka, Minnesota, USA). Of 52 patients with SLE not on statins

Table 2 Baseline characteristics of patients with SLE

\section{Characteristics of patients with SLE $(n=72)$}

\begin{tabular}{ll}
\hline & N (\%) or mean \pm SD \\
\hline Disease duration \\
\hline History of & $12.0 \pm 1.9$ \\
\hline Malar rash & \\
\hline Discoid & $27(37.5 \%)$ \\
\hline Mouth ulcers & $9(12.5 \%)$ \\
\hline Alopecia & $41(56.9 \%)$ \\
\hline Arthritis & $39(54.2 \%)$ \\
\hline Serositis & $57(79.2 \%)$ \\
\hline Proteinuria & $36(50.0 \%)$ \\
\hline Seizure & $27(37.5 \%)$ \\
\hline Haemolytic anaemia & $2(2.8 \%)$ \\
\hline Leucopaenia & $6(8.3 \%)$ \\
\hline Thrombocytopaenia & $37(51.4 \%)$ \\
\hline ANA & $15(20.8 \%)$ \\
\hline Anti-dsDNA & $70(97.2 \%)$ \\
\hline Lupus anticoagulant & $38(52.8 \%)$ \\
\hline Anticardiolipin & $24(33.3 \%)$ \\
\hline Anti-B2 glycoprotein & $51(71.8 \%)$ \\
\hline Low C3 & $24(33.3 \%)$ \\
\hline Low C4 & $46(63.9 \%)$ \\
\hline Direct Coomb's test & $35(48.6 \%)$ \\
\hline At baseline CTA & $12(16.7 \%)$ \\
\hline SELENA-SLEDAI & \\
\hline PGA & $1.7 \pm 2.1$ \\
\hline Hydroxychloroquine use & $0.6 \pm 0.7$ \\
\hline Prednisone use & $63(87.5 \%)$ \\
\hline Statin use & $26(36.1 \%)$ \\
\hline Antihypertensive use & $15(20.8 \%)$ \\
\hline Imunosuppressant use & $20(27.8 \%)$ \\
\hline
\end{tabular}

*Disease duration at the time of baseline CTA.

CTA, CT angiography; PGA, physician global assessment; SELENA-SLEDAI, Safety of Estrogens in Lupus National Assessment-Systemic Lupus Erythematosus Disease Activity Index; SLE, systemic lupus erythematosus. 
Table 3 Plaque volumes (in $\mathrm{mm}^{3}$ ) between study groups at baseline

\begin{tabular}{|c|c|c|c|c|c|c|}
\hline & \multicolumn{3}{|c|}{ Unadjusted associations } & \multicolumn{3}{|c|}{ Adjusted associations* } \\
\hline & $\begin{array}{l}\text { SLE group } \\
(\mathrm{n}=72) \\
\text { Mean estimate } \\
(95 \% \mathrm{Cl})\end{array}$ & $\begin{array}{l}\text { Control group }(n=100) \\
\text { Mean estimate } \\
(95 \% \mathrm{Cl})\end{array}$ & $P$ value & $\begin{array}{l}\text { SLE group } \\
(\mathrm{n}=72) \\
\text { Mean estimate } \\
(95 \% \mathrm{Cl})\end{array}$ & $\begin{array}{l}\text { Control group } \\
(n=100) \\
\text { Mean estimate } \\
(95 \% \mathrm{Cl})\end{array}$ & $P$ value \\
\hline $\begin{array}{l}\text { Total plaque } \\
\text { volume }\end{array}$ & $\begin{array}{l}1483.5 \\
\text { (1381.7 to } 1585.3)\end{array}$ & $\begin{array}{l}477.4 \\
\text { (391.0 to } 563.9 \text { ) }\end{array}$ & $<0.0001$ & $\begin{array}{l}1695.3 \\
(1521.6 \text { to } 1868.9)\end{array}$ & $\begin{array}{l}359.6 \\
\text { (211.7 to } 507.6 \text { ) }\end{array}$ & $<0.0001$ \\
\hline NCP volume & $\begin{array}{l}1473.8 \\
\text { (1392.2 to } 1555.3 \text { ) }\end{array}$ & $\begin{array}{l}196.8 \\
(127.8 \text { to } 266.0)\end{array}$ & $<0.0001$ & $\begin{array}{l}1630.4 \\
(1494.1 \text { to } 1766.7)\end{array}$ & $\begin{array}{l}135.5 \\
(19.4 \text { to } 251.6)\end{array}$ & $<0.0001$ \\
\hline
\end{tabular}

${ }^{\star}$ Adjusted for sex, ethnicity, diabetes, statin use at baseline and age at baseline.

NCP, non-calcified plaque; SLE, systemic lupus erythematosus.

at baseline, 19 patients were started on statins after the first CCTA.

A total of 100 consecutive controls with no known history of lupus, heart disease or revascularisation ${ }^{12}$ who had two coronary CT angiograms at least 1 year apart (mean $=1.11$ years, $\mathrm{SD}=0.25$ years) were included in the study. These were asymptomatic patients referred by their primary physicians for screening of coronary artery disease and the screening interval was decided by the primary physicians. The methodology for image acquisition was similar ${ }^{1213}$ and three-dimensional image analysis was performed on identical workstation (Vitrea FX V.3.0 workstation, Vital Images, Minnetonka, Minnesota, USA). Of 28 controls not on statins at baseline, 6 were started on statins after the first CCTA. Statin information was only available at the time of the baseline scan or the follow-up, so we could not assess duration of prior statin use for the controls.

All images were interpreted by a physician, blinded to any clinical information, with extensive experience (level III certified) in the interpretation of CCTA. The left anterior descending coronary artery, left circumflex coronary artery and right coronary artery were divided into proximal, mid and distal segments, respectively, according to standard segmentation guidelines. ${ }^{14}$ The left main coronary artery was evaluated separately, resulting in 10 segments evaluated in total. Each segment was assessed for the presence and severity of atherosclerotic plaques on a semiquantitative scale. Plaque characteristics, including remodelling, were noted for each segment. Spotty calcification and the napkin-ring sign were not analysed.

Each non-calcified plaque (NCP) detected within the vessel wall (left anterior descending artery, right coronary artery and left circumflex) was evaluated with the minimum CT density. A plaque density $<30$ HU was considered low attenuation. ${ }^{15}$

Coronary plaque area was measured by manual tracing for the difference between the area within the external elastic membrane and the area of the vessel lumen at the site of maximal luminal narrowing as observed on a cross-sectional CCTA. A LANCP was defined as a lowattenuation $(<30 \mathrm{HU})$ mass $>1 \mathrm{~mm}^{2}$ in size, located within the vessel wall and clearly distinguishable from the contrast-enhanced coronary lumen and the surrounding pericardial tissue.

Lesions with a remodelling ratio $>1.05$ were considered to have positive remodelling, and those in which remodelling was $<0.95$ were considered to have negative remodelling. ${ }^{16}$ Lesions with a remodelling ratio of $0.95-1.05$ were classified as having no remodelling. ${ }^{16}$

Table 4 Mean (SD) of low-attenuation non-calcified plaque at baseline, in each cohort, by age and sex

\begin{tabular}{|c|c|c|c|c|c|c|}
\hline \multirow[b]{3}{*}{ Sex } & \multirow[b]{3}{*}{ Age } & \multicolumn{5}{|c|}{ Low-attenuation non-calcified plaque } \\
\hline & & \multicolumn{2}{|c|}{ SLE } & \multicolumn{2}{|c|}{ Controls } & \multirow{2}{*}{$\begin{array}{c}P \\
\text { value }\end{array}$} \\
\hline & & $\mathbf{n}$ & Mean (SD) & $\mathbf{n}$ & Mean (SD) & \\
\hline \multirow[t]{2}{*}{ Female } & $<45$ & 19 & 393.63 (119.18) & 0 & $-(-)$ & - \\
\hline & $45-59$ & 33 & $450.52(150.37)$ & 3 & $53.37(31.6)$ & $<0.0001$ \\
\hline \multirow[t]{3}{*}{ Male } & $<45$ & 3 & $412.33(216.58)$ & 2 & $51.15(72.34)$ & 0.1176 \\
\hline & $45-59$ & 5 & $516.4(76.83)$ & 22 & $46.84(57.8)$ & $<0.0001$ \\
\hline & $60+$ & 1 & $582(-)$ & 52 & $47.56(57.54)$ & - \\
\hline
\end{tabular}

SLE, systemic lupus erythematosus. 
Table 5 Mean (SD) of remodelling index at baseline in each cohort by age and sex

\begin{tabular}{|c|c|c|c|c|c|c|}
\hline \multirow[b]{3}{*}{ Sex } & \multirow[b]{3}{*}{ Age } & \multicolumn{5}{|c|}{ Remodelling index } \\
\hline & & \multicolumn{2}{|c|}{ SLE } & \multicolumn{2}{|c|}{ Control } & \multirow{2}{*}{$\begin{array}{c}P \\
\text { value }\end{array}$} \\
\hline & & $\mathbf{n}$ & Mean (SD) & $\mathbf{n}$ & Mean (SD) & \\
\hline All & All & 66 & $0.96(0.69)$ & 91 & $0.97(0.28)$ & 0.8412 \\
\hline \multirow[t]{3}{*}{ Female } & $<45$ & 19 & $0.89(0.55)$ & 0 & $-(-)$ & - \\
\hline & $45-59$ & 33 & $0.89(0.78)$ & 3 & $0.85(0.09)$ & 0.8147 \\
\hline & $60+$ & 5 & $1.30(0.59)$ & 20 & $0.85(0.33)$ & 0.1663 \\
\hline \multirow[t]{3}{*}{ Male } & $<45$ & 3 & $0.83(0.42)$ & 2 & $1.28(0.47)$ & 0.3845 \\
\hline & $45-59$ & 5 & $1.34(0.75)$ & 18 & $0.95(0.29)$ & 0.3038 \\
\hline & $60+$ & 1 & $1.26(-)$ & 47 & $1.03(0.24)$ & - \\
\hline
\end{tabular}

SLE, systemic lupus erythematosus.

\section{Statistical analysis}

$\chi^{2}$ test was used to evaluate baseline characteristics between lupus patients and controls. Paired t-test or Wilcoxon signed ranks test was used to compare plaque volume between baseline and follow-up for each cohort. A linear regression model was used to compare the baseline plaque volumes between patients with SLE and controls adjusting for the factors that were found to be significant from the baseline demographics, namely age, sex, ethnicity, diabetes and statin use. In both cohorts, age was a continuous variable. Ethnicity categories were defined as African American, Caucasian and others.

Analysis of variance was used to evaluate the association between LANCP and demographic and clinical variables including sex, race, age at baseline, ever smoking (from history file), diabetes, hypertension, hyperlipidaemia, obesity, lupus anticoagulant, anticardiolipin, anti-beta 2 glycoprotein, hydroxychloroquine and immunosuppressant use, anti-dsDNA, low C3, low C4, antihypertensive and statin use.

\section{RESULTS}

Table 1 describes the baseline characteristics of the patients with SLE and controls. At the time of their baseline CCTA, a higher proportion of controls were male, older, diabetic and on a statin. Also, there were fewer African Americans among controls. Characteristics of patients with SLE are detailed in table 2. The average disease duration at the time of the first CCTA was 12.0 \pm 1.9 years.
Table 3 provides mean total plaque and calcified plaque volume at baseline in patients with lupus and controls. The significantly higher burden of calcified plaque in controls is expected due to the older age and predominantly male population, but the total plaque and NCP burden was significantly higher in the SLE group, even after adjusting for age, sex, ethnicity, diabetes and statin use.

Table 4 displays the mean of the total LANCP volume in $\mathrm{mm}^{3}$ at baseline in patients with SLE and controls. Despite the predominance of elderly males among controls, patients with SLE had a significantly higher burden of LANCP $(\mathrm{p}<0.001)$. Middle-aged women with SLE (age 45-59) had a substantially greater LANCP burden compared with controls although there was no statistically significant difference in patients aged 60 or greater, possibly due to the small number of women with lupus in this group. Importantly, the control group included no women younger than 45 and the number of male patients with SLE was small.

Table 5 provides mean remodelling index at baseline in patients with lupus and controls. No significant differences between the two groups were found but the numbers were small. Among patients with lupus, only women $>60$ and men $>45$ had a mean positive remodelling index while all other age groups had mean negative remodelling.

Table 6 details the changes in LANCP and remodelling index between the two CCTA in lupus and controls, respectively. No significant change was seen in LANCP volume in SLE, while a significant regression in LANCP volume was seen in the control group. No significant changes were seen over time in remodelling index in either group.

Table 7 shows the association between patient and disease-specific variables with LANCP. LANCP was associated with age $(\mathrm{p}<0.05)$ and current prednisone dose $>10 \mathrm{mg}$ /day. There were only five cardiovascular events in the studied group so the association of LANCP and positive remodelling index could not be assessed.

\section{DISCUSSION}

CCTA has emerged as the best non-invasive imaging modality in terms of assessing both lumen area and plaque composition. ${ }^{17}$ Absence of atherosclerosis on CCTA has a negative prognostic value approaching $100 \%$, even in prolonged follow-up. ${ }^{18}$ Pundziute et $a l^{9}$ demonstrated

Table 6 Volume progression/regression $\left(\mathrm{mm}^{3}\right)$ within each cohort

\begin{tabular}{llllllll}
\hline & \multicolumn{2}{l}{ SLE } & & & \multicolumn{2}{l}{ Control } \\
\cline { 2 - 3 } & $\mathbf{n}$ & Mean diff (SD) & P value & & & Mean diff (SD) & P value \\
\hline Change in total NCP plaque & 70 & $6.27(322.46)$ & 0.8712 & & 100 & $-32.84(110.67)$ & $<0.0001$ \\
Change in LANCP plaque & 27 & $-13.56(93.29)$ & 0.4570 & & 100 & $-6.90(27.62)$ & $\mathbf{0 . 0 0 0 2}$ \\
Change in remodelling index & 30 & $0.09(0.87)$ & 0.6013 & & 83 & $-0.03(0.38)$ & 0.4062 \\
\hline
\end{tabular}

LANCP, low-attenuation non-calcified plaque; SLE, systemic lupus erythematosus. 


\begin{tabular}{|c|c|c|c|}
\hline $\begin{array}{l}\text { Demographic and } \\
\text { clinical variables }\end{array}$ & Subgroup & $\begin{array}{l}\text { LANCP } \\
\text { mean } \\
\text { (SD) }\end{array}$ & $P$ value \\
\hline \multirow[t]{2}{*}{ Sex } & Female $(n=57)$ & $453(217)$ & 0.6325 \\
\hline & Male $(n=9)$ & $489(136$ & \\
\hline \multirow[t]{3}{*}{ Race } & White $(n=43)$ & 459 (223) & 0.3823 \\
\hline & Black (n=19) & $483(180)$ & \\
\hline & Other $(n=4)$ & $324(107)$ & \\
\hline \multirow[t]{3}{*}{ Age at baseline } & $<45(n=22)$ & 396 (129) & 0.0115 \\
\hline & $45-59(n=38)$ & $459(144)$ & \\
\hline & $60+(n=6)$ & $676(512)$ & \\
\hline \multirow[t]{2}{*}{ History of smoking } & Ever $(n=20)$ & $413(147)$ & 0.2482 \\
\hline & Never $(n=46)$ & $478(228)$ & \\
\hline \multirow{2}{*}{$\begin{array}{l}\text { History of lupus } \\
\text { anticoagulant }\end{array}$} & Yes $(n=23)$ & $504(291)$ & 0.1880 \\
\hline & No $(n=43)$ & $433(143)$ & \\
\hline \multirow[t]{2}{*}{ History of anticardiolipin } & Yes $(n=46)$ & $450(236)$ & 0.6527 \\
\hline & No $(n=20)$ & $476(122)$ & \\
\hline \multirow[t]{2}{*}{ Current cholesterol 200+ } & Yes $(n=12)$ & $465(218)$ & 0.6042 \\
\hline & No $(n=53)$ & $430(168)$ & \\
\hline \multirow[t]{3}{*}{ Current BMI } & $<25(n=25)$ & $430(284)$ & 0.3007 \\
\hline & $25-30(n=21)$ & $434(118)$ & \\
\hline & $>30(n=20)$ & $518(158)$ & \\
\hline \multirow[t]{2}{*}{ Current anti-dsDNA } & Yes $(n=13)$ & $517(375)$ & 0.2558 \\
\hline & No $(n=53)$ & $443(143)$ & \\
\hline \multirow[t]{2}{*}{ Current low complement } & Yes $(n=16)$ & 469 (354) & 0.8116 \\
\hline & No $(n=50)$ & $454(137)$ & \\
\hline \multirow{2}{*}{$\begin{array}{l}\text { Current } \\
\text { hydroxychloroquine use }\end{array}$} & Yes $(n=56)$ & $466(215)$ & 0.4677 \\
\hline & No $(n=10)$ & $414(158)$ & \\
\hline \multirow[t]{2}{*}{ Current prednisone use } & $\begin{array}{l}<10 \mathrm{mg} / \text { day } \\
(\mathrm{n}=62)\end{array}$ & $436(143)$ & 0.0004 \\
\hline & $\begin{array}{l}\geq 10 \mathrm{mg} / \text { day } \\
(\mathrm{n}=4)\end{array}$ & $800(591)$ & \\
\hline \multirow[t]{2}{*}{ Current SLEDAI } & $\leq 3(n=48)$ & 445 (135) & 0.4198 \\
\hline & $>3(n=18)$ & 492 (335) & \\
\hline \multirow{2}{*}{$\begin{array}{l}\text { Hypertension or } \\
\text { antihypertensive use }\end{array}$} & Yes $(n=46)$ & $482(236)$ & 0.1629 \\
\hline & No $(n=20)$ & 404 (107) & \\
\hline
\end{tabular}

BMI, body mass index; LANCP, low-attenuation non-calcified plaque; SLE, systemic lupus erythematosus.

that CCTA provides independent prognostic information over baseline clinical risk factors in patients with known and suspected Coronary Artery Disease (CAD). The type of plaque identified on CCTA has important predictive value with mortality incrementally increasing from calcified plaque $(1.4 \%)$ to partially calcified plaque $(3.3 \%)$ to $\operatorname{NCP}(9.6 \%) .^{20}$

Regarding vulnerable plaques, CCTA can assess the presence, size and thickness of the necrotic core, by grading tissue in $\mathrm{HU}$; plaques with large cores will cause less attenuation and thus have lower unit values. ${ }^{21}$ Specific high-risk plaque criteria have been developed, such as positive remodelling (remodelling index $\geq 1.1^{22}$ ) and (very) low (given that the threshold for $\mathrm{a} \geq 10 \%$ necrotic core is $41 \mathrm{HU})$ attenuation NCP $(<30 \mathrm{HU}) .{ }^{17}$

A recent CCTA study, with a follow-up of almost 100 months, ${ }^{23}$ confirmed that, in non-obstructive disease, positive remodelling index, increased plaque burden and LANCP were all independently associated with cardiac events. Presence of both positive remodelling index and LANCP yielded a more than $22 \%$ probability of acute coronary syndrome (ACS) over an average follow-up of 27 months, as compared with $<0.5 \%$ probability, should both features be absent. ${ }^{1}$

In a previous analysis of presence or absence of NCP in SLE, we found that $54 \%$ of patients with SLE had NCP, ${ }^{24}$ that $53 \%$ of patients who had no coronary calcification had $\mathrm{NCP}^{25}$ and that NCP was present more often in those with higher disease activity, current immunosuppressive use and current nonsteroidal anti-inflammatory drugs (NSAID) use, ${ }^{24}$ although a subsequent quantitative analysis failed to show an association with measures of SLE disease activity. ${ }^{25}$ Patient age, current methotrexate use, history of anti-dsDNA positivity and obesity were associated with the presence of non-calcified coronary plaque, in the multivariate model. ${ }^{25}$ We thus decided to assess for the first time high-risk plaque characteristics in patients with SLE, namely LANCP and positive remodelling index, and compare their burden with a control population.

Total plaque and NCP burden were significantly higher among patients with SLE even after adjusting for age, sex, ethnicity, diabetes and statin use. LANCP burden at baseline was also significantly higher in patients with SLE compared with controls, even though our control group consisted mostly of elderly men. LANCP volume was significantly higher in patients with SLE over 60 years of age $(\mathrm{p}<0.01)$ and in those with current prednisone dose $>10 \mathrm{mg}$ /day. There was no association with any measure of SLE disease activity, antiphospholipid antibodies, smoking, hypertension, hypercholesterolemia or immunosuppressant use. The number of cardiovascular events was small $(n=5)$, so the association with low-attenuation plaque and positive remodelling index could not be assessed.

LANCP burden remained stable over follow-up in contrast to controls, where there was significant regression of LANCP over time. Statin use had no association with LANCP regression over time in patients with SLE or in controls.

While a mean negative remodelling index was seen in women $<60$ years of age and men $<45$ years of age, the mean remodelling index in women over 60 years of age was $1.3(\mathrm{SD}=0.59)$ and in men $>45$ years of age, it was 1.34 $(\mathrm{SD}=0.75)$. There were no significant differences compared with controls and no associations with any demographic characteristic, traditional cardiovascular risk factor or SLEspecific risk factor. Remodelling index remained stable over time in both patients with SLE and controls. 


\section{Limitations}

We acknowledge several study limitations. Our control group is not matched to the characteristics of the study population which hinders optimal comparison. We used regression to compare the two groups, but some of the cell sizes are extremely small. For instance, among controls, only $2 \%$ (2 patients) were less than age 45 , with only 5 African Americans (5\%) and a relatively low representation for female sex at 24 patients (24\%). Among patients with lupus, only $2.8 \%$ (two patients) were diabetic. Adverse event rate is very low in our study and associations of plaque findings with patient outcome cannot be assessed. Finally, the value of CT characteristics of coronary atherosclerotic plaque vulnerability remains uncertain. While they have shown promise for prognostic information compared with established predictors, their incremental value may be small. ${ }^{26}$

\section{CONCLUSION}

This is the first study describing high-risk CCTA features of coronary plaque in patients with SLE. Both LANCP and positive remodelling are common in SLE. Importantly, these characteristic vessel changes seen in unstable coronary plaques persisted over time and were not associated with any disease-specific risk factor. Their presence may identify patients with SLE at highest risk of cardiovascular events and those in need for more frequent cardiac monitoring.

Contributors All authors were involved in drafting the article or revising it critically for important intellectual content, and all authors approved the final version to be published. GS had full access to all of the data in the study and takes responsibility for the integrity of the data and the accuracy of the data analysis. Study conception and design: GS. Acquisition of data: GS, MAP, AA-Z, MB. Analysis and interpretation of data. GS, MAP, JL.

Funding The Hopkins Lupus Cohort is supported by a grant from the National Institute of Health (NIH AR 43727 and 69572). This publication was also made possible by Grant Number UL1 RR 025005 from the National Center for Research Resources (NCRR), a component of the National Institutes of Health (NIH), and NIH Roadmap for Medical Research. GS is a Jerome L. Greene Foundation Scholar.

Competing interests None declared.

Patient and public involvement Patients and/or the public were not involved in the design, or conduct, or reporting, or dissemination plans of this research. Patient consent for publication Not required.

Provenance and peer review Not commissioned; externally peer reviewed. Data availability statement All data relevant to the study are included in the article or uploaded as supplementary information.

Open access This is an open access article distributed in accordance with the Creative Commons Attribution 4.0 Unported (CC BY 4.0) license, which permits others to copy, redistribute, remix, transform and build upon this work for any purpose, provided the original work is properly cited, a link to the licence is given, and indication of whether changes were made. See: https://creativecommons.org/ licenses/by/4.0/.

\section{ORCID iDs}

George Stojan http://orcid.org/0000-0001-5758-5052

Michelle A Petri http://orcid.org/0000-0003-1441-5373

\section{REFERENCES}

1 Motoyama S, Sarai M, Harigaya $\mathrm{H}$, et al. Computed tomographic angiography characteristics of atherosclerotic plaques subsequently resulting in acute coronary syndrome. J Am Coll Cardiol 2009;54:49-57.

2 Stefanadis C, Antoniou C-K, Tsiachris D, et al. Coronary atherosclerotic vulnerable plaque: current perspectives. J Am Heart Assoc 2017;6. doi:10.1161/JAHA.117.005543. [Epub ahead of print: 17 Mar 2017].

3 Noguchi T, Nakao K, Asaumi Y, et al. Noninvasive coronary plaque imaging. J Atheroscler Thromb 2018;25:281-93.

4 Schoenhagen P, Nissen SE, Tuzcu EM. Coronary arterial remodeling: from bench to bedside. Curr Atheroscler Rep 2003;5:150-4.

5 Abdeldayem EH, Ibrahim AS, Ahmed AM, et al. Positive remodeling index by MSCT coronary angiography: a prognostic factor for early detection of plaque rupture and vulnerability. Egypt j radiol nucl med 2015;46:13-24.

6 Varnava AM, Mills PG, Davies MJ. Relationship between coronary artery remodeling and plaque vulnerability. Circulation 2002;105:939-43.

7 Cilla M, Peña E, Martínez MA, et al. Comparison of the vulnerability risk for positive versus negative atheroma plaque morphology. $J$ Biomech 2013;46:1248-54.

8 Yamamoto H, Kitagawa T, Ohashi N, et al. Noncalcified atherosclerotic lesions with vulnerable characteristics detected by coronary CT angiography and future coronary events. J Cardiovasc Comput Tomogr 2013;7:192-9.

9 Stojan G, Petri M. Atherosclerosis in systemic lupus erythematosus. $J$ Cardiovasc Pharmacol 2013;62:255-62.

10 Petri M. Hopkins lupus cohort. 1999 update. Rheum Dis Clin North Am 2000;26:199-213.

11 Petri M, Orbai A-M, Alarcón GS, et al. Derivation and validation of the systemic lupus international collaborating clinics classification criteria for systemic lupus erythematosus. Arthritis Rheum 2012;64:2677-86.

12 Zeb I, Li D, Nasir K, et al. Effect of statin treatment on coronary plaque progression - a serial coronary CT angiography study. Atherosclerosis 2013;231:198-204.

13 Budoff MJ, Dowe D, Jollis JG, et al. Diagnostic performance of 64-multidetector row coronary computed tomographic angiography for evaluation of coronary artery stenosis in individuals without known coronary artery disease: results from the prospective multicenter accuracy (assessment by coronary computed tomographic angiography of individuals undergoing invasive coronary angiography) trial. J Am Coll Cardiol 2008;52:1724-32.

14 Raff GL, Abidov A, Achenbach S, et al. SCCT guidelines for the interpretation and reporting of coronary computed tomographic angiography. J Cardiovasc Comput Tomogr 2009;3:122-36.

15 Motoyama S, Ito H, Sarai M, et al. Plaque characterization by coronary computed tomography angiography and the likelihood of acute coronary events in mid-term follow-up. J Am Coll Cardiol 2015;66:337-46.

16 Schoenhagen P, Ziada KM, Vince DG, et al. Arterial remodeling and coronary artery disease: the concept of "dilated" versus "obstructive" coronary atherosclerosis. J Am Coll Cardiol 2001;38:297-306.

17 Rodriguez-Granillo GA, Carrascosa P, Bruining N, et al. Defining the non-vulnerable and vulnerable patients with computed tomography coronary angiography: evaluation of atherosclerotic plaque burden and composition. Eur Heart J Cardiovasc Imaging 2016;17:481-91.

18 Andreini D, Pontone G, Mushtaq S, et al. A long-term prognostic value of coronary CT angiography in suspected coronary artery disease. JACC Cardiovasc Imaging 2012;5:690-701.

19 Pundziute G, Schuijf JD, Jukema JW, et al. Prognostic value of multislice computed tomography coronary angiography in patients with known or suspected coronary artery disease. J Am Coll Cardiol 2007;49:62-70.

20 Ahmadi N, Nabavi V, Hajsadeghi F, et al. Mortality incidence of patients with non-obstructive coronary artery disease diagnosed by computed tomography angiography. Am J Cardiol 2011;107:10-16.

21 Choi B-J, Kang D-K, Tahk S-J, et al. Comparison of 64-slice multidetector computed tomography with spectral analysis of intravascular ultrasound Backscatter signals for characterizations of noncalcified coronary arterial plaques. Am J Cardiol 2008;102:988-93.

22 Kashiwagi M, Tanaka A, Kitabata $\mathrm{H}$, et al. Feasibility of noninvasive assessment of thin-cap fibroatheroma by multidetector computed tomography. JACC Cardiovasc Imaging 2009;2:1412-9.

23 Conte E, Annoni A, Pontone G, et al. Evaluation of coronary plaque characteristics with coronary computed tomography angiography in patients with non-obstructive coronary artery disease: a long-term follow-up study. Eur Heart J Cardiovasc Imaging 2017;18:1170-8.

24 Kiani AN, Vogel-Claussen J, Magder LS, et al. Noncalcified coronary plaque in systemic lupus erythematosus. $J$ Rheumatol 2010;37:579-84. 
25 Kiani AN, Vogel-Claussen J, Arbab-Zadeh A, et al. Semiquantified noncalcified coronary plaque in systemic lupus erythematosus. $J$ Rheumatol 2012;39:2286-93.
26 Lee S-E, Sung JM, Rizvi A, et al. Quantification of coronary atherosclerosis in the assessment of coronary artery disease. Circ Cardiovasc Imaging 2018;11:e007562. 